\title{
Unidos em torno da mesa: a dinâmica familiar na obesidade
}

\author{
Ana Flávia Nascimento Otto \\ Maria Alexina Ribeiro \\ Universidade Católica de Brasília
}

\begin{abstract}
Resumo
A partir da Abordagem Sistêmica da Família, é apresentado o estudo de caso de um paciente com obesidade grave que está se preparando para realizar a cirurgia de redução de estômago em um hospital público de Brasília-DF. A coleta dos dados foi realizada em duas visitas domiciliares para construção do genograma familiar, colagem feita pela família e realização de duas tarefas. O estudo demonstra a forte ligação entre alimentação e pertencimento familiar, além de reforçar aspectos da dinâmica familiar de sistemas com membros obesos descritos na literatura, como: fronteiras internas difusas e externas rígidas; poucas atividades de lazer; ênfase à lealdade familiar; obesidade vista como único problema familiar e evitação de conflitos. Por fim, as autoras sugerem a ampliação à inclusão da terapia familiar no pré e pós-operatório de pacientes com obesidade grave.
\end{abstract}

Palavras-chave: obesidade; dinâmica familiar; terapia familiar.

\begin{abstract}
United around the table: the family dynamics in Obesity. From the perspective of the Family Systems Approach, a case study of a patient with severe obesity being prepared to perform surgery to reduce stomach in a public hospital in Brasilia-DF is presented. Data collection was performed in two home visits to construction of the genogram, family collage made by family and carry out two tasks. The study demonstrates the strong link between food and family membership, and strengthen aspects of family dynamics of systems with obese members of the literature, such as diffuse internal borders and external rigid, few leisure activities, emphasis on family loyalty; obesity seen as single family problem avoidance conflict. Finally, the authors suggest to expand the inclusion of family therapy in the preoperative and postoperative patients with severe obesity.

Keywords: obesity; family dynamic; family therapy.
\end{abstract}

$\mathrm{A}$ obesidade é uma doença de difícil controle, com altos percentuais de insucessos terapêuticos e de recidivas, podendo apresentar sérias repercussões orgânicas e psicossociais, especialmente nas formas mais graves (Bernardi, Cicherelo, \&Vitolo, 2005).

Um importante aspecto a ser considerado no surgimento e manutenção dessa patologia é a associação entre alimentação e afeto. Donato, Osorio, Paschoal e Marum (2004) afirmam que algumas famílias, desde a interação da mãe com o bebê, recompensam e elogiam o ato de alimentar-se de forma muito acentuada, criando na criança uma sensação de bem estar e afetividade associada ao alimento. Além disso, para os autores, a alimentação também está associada à socialização e, por isso, as pessoas saem frequentemente com os amigos para se alimentar. Por isso, quando se sentem sozinhas podem buscar no alimento uma forma de compensação pela falta que sentem das pessoas, e isso pode desencadear o aumento excessivo do peso corporal.

Para Hamburger (1951), a fome é a expressão fisiológica da necessidade do corpo por energia (comida) e o apetite é um desejo psicológico de comer, o qual dá um prazer antecipatório distinto. $\mathrm{O}$ autor esclarece que o estado emocional da pessoa se reflete no seu apetite, aumentando-o ou diminuindo-o, como nos mostra a experiência universal do amor e da dor. Esse estudo confirma a afirmação de Alexander (1989) de que a alimentação desempenha um papel central na área emocional do indivíduo.

Kathalian (1992) corrobora com essa linha de pensamento e afirma que o ato de comer, para os obesos, é tido como tranquilizador, como uma forma de localizar a ansiedade e a angústia no corpo, principalmente as relacionadas com dificuldades de lidar com a frustração e com os limites. Nesse sentido, Conrad (1954) enfatizou o papel da hostilidade na hiperfagia, mostrando que a agressividade e hostilidade reprimida são duas das mais frequentes e importantes causas do comer em excesso. De acordo com a autora, para que o tratamento da obesidade seja efetivo, os profissionais de saúde devem ter a compreensão dos aspectos psicológicos da doença.

A obesidade, por ter uma etiologia multifatorial, possui um tratamento que envolve vários tipos de abordagens. A orientação dietética, a programação de atividade física e o uso de fármacos têm sido as principais estratégias utilizadas no tratamento convencional (Segal \& Fandiño, 2002).

Entretanto, 95\% dos pacientes com obesidade grave não 
respondem satisfatoriamente a esse tratamento, recuperando seu peso inicial em até 2 anos (Segal \& Fandiño, 2002). Devido à necessidade de uma intervenção mais eficaz na condução clínica desses pacientes, a cirurgia bariátrica vem sendo cada vez mais indicada.

São candidatos ao tratamento cirúrgico os pacientes com o IM maior que $39,9 \mathrm{~kg} / \mathrm{m} 2$ ou com IMC superior a $34,9 \mathrm{~kg} / \mathrm{m} 2$ associado à comorbidade, tais como apneia do sono, diabetes mellitus tipo 2, hipertensão arterial, dislipidemias e dificuldades de locomoção, entre outras de difícil manejo clínico (Segal \& Fandiño, 2002).

A cirurgia bariátrica envolve um acompanhamento multiprofissional do paciente tanto antes quanto depois do procedimento cirúrgico. O objetivo no período pré-operatório é aumentar o potencial de sucesso da cirurgia. Para isso, o paciente precisa ser informado das mudanças significativas que ele atravessará e dos riscos relacionados ao procedimento. Um acompanhamento psicológico fornece condições para que o paciente perceba a amplitude do processo pelo qual passará e o ajuda a tomar decisões mais conscientes. (Oliveira, Linardi, \& Azevedo, 2004).

O tratamento nutricional também é essencial nessa fase. Visa diminuir o risco cirúrgico por meio da perda de peso inicial, da identificação de transtornos alimentares, da promoção de expectativas reais de perda de peso. Além disso, o aconselhamento permite a preparação do paciente para a alimentação no pós-operatório (Cronin \& Mac Donough, 1987).

Nesse sentido, Shikora (2000) afirma que o resultado póscirúrgico depende da compreensão do paciente sobre as restrições dietéticas impostas pela cirurgia, os desconfortos fisiológicos potenciais e as consequências que podem ser experimentadas se a indicação dietética não for seguida. Segundo Cruz e Marimoto (2004) existe uma alta incidência de complicações pósoperatórias, entre elas: náuseas, vômitos, síndrome de Dumping, diarreia, constipação, obstrução gástrica e ruptura da linha de grampeamento. Também ocorre com frequencia a deficiência de alguns micronutrientes específicos, tais como: ácido fólico, ferro e vitamina B12. Assim, a intervenção nutricional na fase pós-operatória mostra-se ainda mais necessária.

Segundo Cordás, Lopes Filho e Segal (2004), com o crescente uso das cirurgias bariátricas começam a ser descritos casos de transtornos alimentares na evolução pós-cirúrgica. Conforme os autores, não é possível prever a ocorrência de transtornos alimentares ou outros transtornos psiquiátricos no pós-operatório, mas a existência dessas patologias no préoperatório deve alertar para uma maior observação do paciente após a cirurgia. O padrão alimentar desordenado tende a permanecer após a operação, aumentando em quatro vezes o risco de complicações pós-operatórias, além de facilitar o reganho de peso a longo prazo. Nesse sentido, os autores salientam que para um melhor acompanhamento de pacientes obesos com transtornos psiquiátricos, é necessário um atendimento multiprofissional que inclua a família no processo terapêutico.

A terapia conjugal e familiar tem alcançado bons resultados no tratamento de transtornos alimentares. A inclusão da família amplia a compreensão do sintoma, e possibilita a modificação de padrões relacionais importantes na determinação, desenvolvimento e manutenção desses transtornos (Cobelo, Saikali, \& Shomer, 2004).

Diversos estudos investigaram o funcionamento do sistema familiar de pessoas com obesidade, principalmente quando se trata de obesidade infantil. Em relação à obesidade na fase adulta, nossa revisão encontrou as seguintes características da dinâmica familiar: rigidez, superproteção, evitação do conflito, isolamento social, assertividade e raiva inibidas, baixa expressão de sentimentos, triangulação (Barbarin \& Tirado, 1985; Ganley,1986; 1992; Marshall \& Neill,1977; Otto, 2007). Além disso, índices elevados de adaptabilidade na escala FES II foram relacionados a um início mais adiantado da obesidade e mais atitudes perturbadas na alimentação (Johnson, Brownell, St. Jeor, Brunner, \&Worby, 1997).

Nesse contexto, conscientes da importância do processo de adaptação e da coesão familiar para o sucesso do tratamento em longo prazo, definimos como objetivo desse estudo investigar a dinâmica de uma família que apresenta um membro com obesidade grave, em termos de coesão familiar, adaptabilidade, fronteiras, comunicação, padrões trangeracionais, resolução de conflitos e alimentação.

\section{Método}

O delineamento de pesquisa escolhido foi o estudo de caso, devido à complexidade do problema e à necessidade de um aprofundamento quanto às interações familiares.

\section{Participantes}

Foi convidada a participar da pesquisa a família de um paciente com obesidade grave que estava em acompanhamento em um hospital público de Brasília-DF. O participante estava na fase de preparação para a realização dessa cirurgia, quando foi convidado para participar da pesquisa. $\mathrm{O}$ grupo familiar é composto por: Carlos ${ }^{1}, 38$ anos, sua mãe D. Lila, seus 8 irmãos, 4 cunhadas, 2 cunhados e 15 sobrinhos. Nem todos estiveram presentes nos dois encontros. Quanto aos que participaram, alguns só estiveram presentes no primeiro encontro, outros somente no segundo e outros em ambos. Moram com Carlos, na casa de D. Lila, sua irmã Almerinda com sua filha Gabriela, seu irmão Sílvio com sua namorada Sabrina, e Rafael, filho de seu irmão Lúcio.

\section{Instrumentos}

Foram utilizados os seguintes instrumentos: roteiro para elaboração do genograma familiar (Carter \& McGoldrick, 1989/1995), roteiro para realização da colagem da família, tarefa no 2 de Féres-Carneiro (1983) e tarefa no 4 de Watzlawick (conforme Féres-Carneiro, 1983). A tarefa de Féres-Carneiro consiste em perguntar para o grupo familiar "Quando você está fazendo uma coisa qualquer, mas fica difícil terminar sozinho, o que você faz?" e fazer circular as respostas de forma a garantir a participação de todos. Na tarefa de Watzlawickpede-se que as crianças saiam da sala. Apresenta-se à família o seguinte provérbio: "Uma pedra que rola não cria lodo". Pede-se que discutam o provérbio e cheguem a uma conclusão sobre seu significado. As informações colhidas nos encontros com a família 
foram registradas por filmadora, gravador com fita e mp3.

\section{Procedimentos}

O projeto foi submetido ao Comitê de Ética em Pesquisa - CEP, da Faculdade de Medicina da Universidade de Brasília, para apreciação. A pesquisadora entrou em contato com os participantes por meio telefônico e marcou um encontro com toda a família. Foram realizadas duas visitas à residência da família participante. Antes de iniciar o processo de coleta de dados, as entrevistadoras - composta pela pesquisadora e uma psicóloga terapeuta familiar, explicou todas as condições da pesquisa. Na primeira visita foi utilizado o genograma para coleta de informações sobre a dinâmica familiar. Na segunda visita foi realizada a colagem da família, a tarefa $\mathrm{n}^{0} 2$ de FéresCarneiro (1983) e a tarefa $\mathrm{n}^{\mathrm{o}} 4$ de Walzlawick (conforme citado por Féres-Carneiro, 1983).

\section{Análise dos dados}

Todos os dados foram analisados conforme os objetivos específicos desse estudo e interpretados de acordo com os autores que fizeram parte do referencial teórico: Ciclo de vida familiar (Carter \& McGoldrick, 1995); adaptabilidade (Ackerman, 1986; Andolfi,Angelo, Menghi,\&Nicolo-Corigliano, 1983/1984; Minuchin, 1974/1982); coesão (Andolfi et al., 1983/1984; Bowen, 1979/1991; Boszormenyi-Nagy\&Spark, 1973; Minuchin, 1974/1982); fronteiras (Minuchin,1974/1982); comunicação (Satir, 1964/1980; Watzlawick, Beavin, \& Jackson, 1967/1993; Whitaker \& Bumberry,1988/1990); resolução de conflitos (Ackerman, 1986; Satir, 1964/1980); padrões transgeracionais (Bowen, 1979/1991); alimentação (Alexander, 1989; Campos, 1993; Conrad, 1954; Donato, Osório, Paschoal, \& Marum, 2004; Hamburger, 1951; Kathalian, 1992).

\section{Estudo de caso}

A família Oliveira apresenta um histórico de doenças relacionadas à obesidade. Nas quatro gerações ocorrem obesidade, hipertensão arterial, diabetes, hipotireoidismo e doenças cardíacas, em sua maioria, ligadas à doença de chagas, muito comum na região onde as famílias de origem moravam.

A família relata que todos começaram a engordar quando começaram a trabalhar, porque passaram a comprar alimentos que antes não tinham condições financeiras para adquirir. Apesar da vida difícil que levaram, a família relata nunca ter "passado fome". Hoje a casa da mãe está sempre abastecida com uma grande variedade de frutas e outros alimentos.

Além de várias pessoas com obesidade, a família apresenta problemas de ordem emocional, principalmente na quarta geração. Três sobrinhas de Carlos fazem tratamento psicológico num centro de tratamento para adolescentes de Brasília. Além delas, um sobrinho "está bebendo e engordando muito", o que vem preocupando toda a família.

A família se encontra no estágio "Famílias no estágio tardio da vida" (Carter \& McGoldrick, 1995), onde os avós procuram se adequar à aposentadoria e aceitar suas condições físicas. Entretanto, a mãe, D. Lila, permanece fazendo as tarefas da casa e cuidando dos filhos e netos.
Em relação à adaptabilidade, a família parece apresentar algumas dificuldades. Três filhos adultos ainda moram com a mãe, sendo uma com sua filha adolescente que teve com um namorado. Sílvio, o filho caçula dos homens, trouxe a namorada para morar com ele na casa da mãe. Além dos filhos e da neta, D. Lila cria o neto Rafael, filho de Lúcio. Dessa forma, parece que a família não conseguiu se adaptar ao estágio do Ciclo de Vida "lançando os filhos e seguindo em frente" (Carter \& McGoldrick, 1995), em que os filhos ganham autonomia e se separam da família de origem.

Um aspecto interessante é a forma como a família se organiza para a realização de tarefas. Para cada atividade existe um subgrupo que fica responsável pelo gerenciamento, o que permite que a liderança passe por diferentes membros da família. Na colagem, a sobrinha de Carlos, Ágatha, tomou a iniciativa para organizar o cartaz. Enquanto todos os demais escolhiam e cortavam as figuras, ela colava os recortes ordenadamente (Figura 1). Todos participaram ativamente da tarefa com exceção de Almerinda que ficou só observando. A família escolheu como título da colagem a figura escolhida por Ágatha que diz: "Na casa da mamãe".

Toda a família gira em torno de D. Lila, a matriarca. Essa posição central ficou clara na tarefa no 2 , quando foi perguntado aos membros da família a quem eles pedem ajuda quando estão fazendo algo que não conseguem terminar sozinhos. Todos responderam que pedem ajuda uns aos outros, mas principalmente à mãe. Segundo Mônica:

"Se filho tá dando problema, marido tá dando problema, irmão tá dando problema, eu falo logo para mamãe: o que nós vamos fazer? Está acontecendo isso, isso e isso."

D. Lila comenta: "Eles tentam esconder de mim, mas não adianta esconder eu vejo tudo."

Quanto aos papéis familiares, eles são bem demarcados. Almerinda é a irmã "zangada", Sílvio é o "atleta", Mônica é a "cuidadora”, Lúcio o "piadista”, etc. Mônica fala sobre Lúcio: "Não liga para Lúcio não, ele é o piadista da família. Tudo ele faz piada.".

O sistema familiar apresenta um funcionamento aglutinado. Todos concordaram que a colagem expressou bem o que é o sistema, "a união familiar". As fronteiras internas são difusas e as fronteiras externas, rígidas. O sistema não possui muitas relações com o ambiente social — elas se resumem ao trabalho e à escola e os membros não revelaram ter amigos fora da família, como mostra o recorte "vizinhos distantes", que Mira colocou na colagem (Figura 1) e a fala de Mônica: "A gente conhece todo mundo da rua, mas ninguém é de ficar na casa de ninguém, não".

Além disso, fazem todas as viagens juntos e o principal lazer da família é "passar o fim de semana juntos conversando". Apenas os "filhos homens", com exceção de Carlos, fazem programas de lazer fora do âmbito familiar. Todos os relacionamentos extra-familiares são estimulados a serem incluídos no sistema.

Durante as duas visitas a família mostrou-se descontraída e alegre. A comunicação é abundante, todos falam ao mesmo tempo, não respeitando o espaço do outro. Fazem piada uns dos outros, utilizando termos como: "ela não deu para nada" referindo-se à Mira que não casou e não teve filhos.

$\mathrm{Na}$ colagem Sílvio escolheu uma figura que dizia "onde 


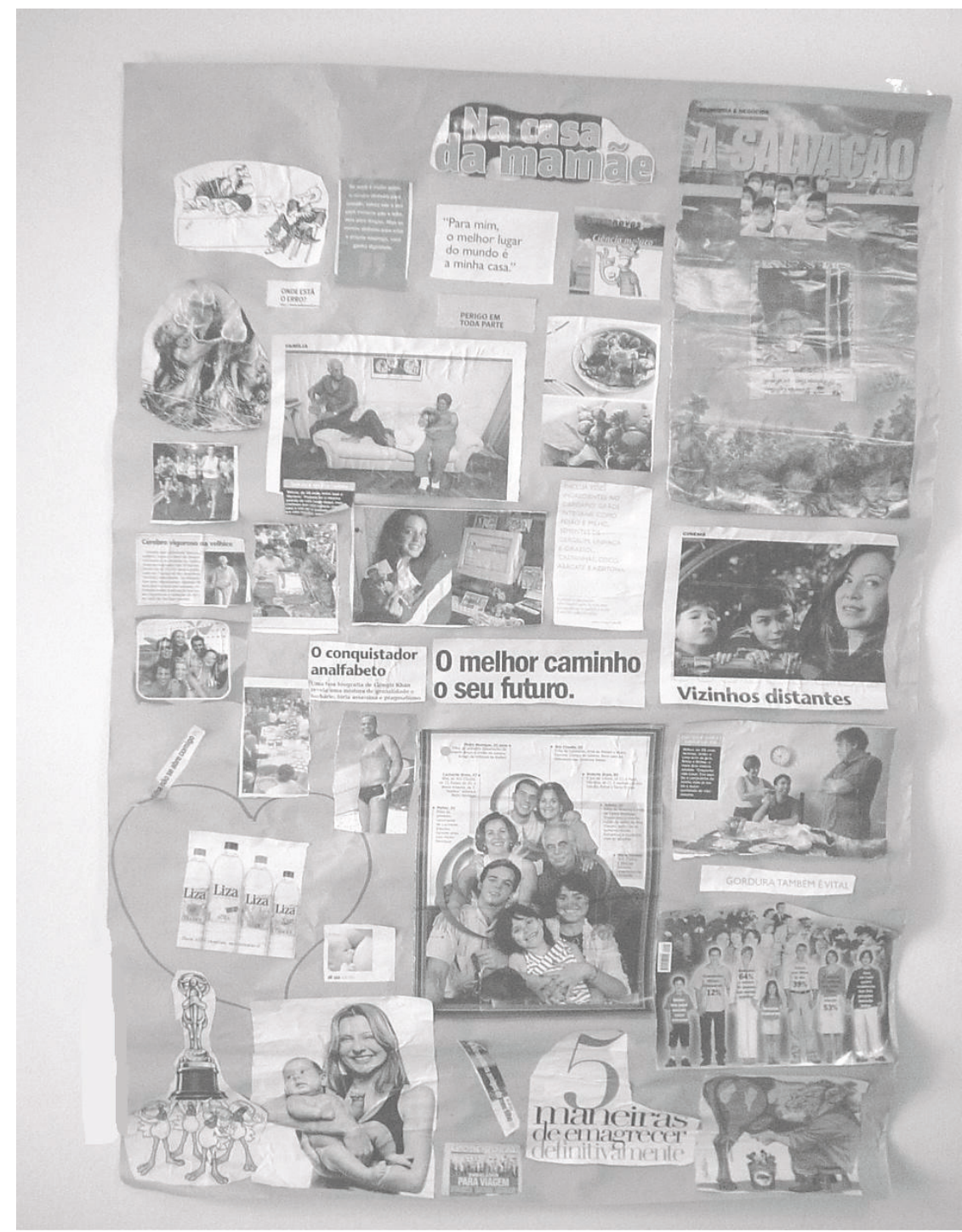

Figura 1. Colagem da Família Oliveira

está o erro?", para falar sobre a obesidade na família. Quando foi questionado se eles possuem outros problemas além da alimentação, houve silêncio. Os membros se olharam imóveis. Sílvio disse, depois de alguns segundos, muito constrangido que "toda família tem seus problemas".

Durante a construção do genograma, Mira falou sobre a alimentação de Carlos:

"Se o médico disser que ele só pode comer frango no almoço, ele não come 3, 4 pedaços, não. Ele come o frango inteiro.”Carlos respondeu: “O problema é esse! Se eu como 2 pedaços, eles dizem que eu comi o frango inteiro. Daí, eu digo, então tá bom, eu comi o frango inteiro. Eu concordo para não criar confusão".

As pesquisadoras, então, perguntaram aos familiares sobre o comportamento de Carlos em relação aos conflitos. Todos afirmaram que ele sempre concorda para evitar briga. Em outro momento, quando Carlos falava sobre seu tratamento e acusou os irmãos de não verem o seu esforço, quando os ânimos começaram a se acirrar, rapidamente Mônica fez uma brincadeira para diminuir a tensão das relações. Esses episódios demonstram a dificuldade da família de lidar com o conflito, e por isso a necessidade de evitá-lo.

$\mathrm{O}$ alimento permeia todas as relações da família. $\mathrm{Na}$ colagem (Figura 1), 14 das 35 figuras (40\%) estão relacionadas à alimentação, expressando fome, abundância de alimentos, $\mathrm{o}$ ato de comer e a importância da "gordura". Sílvio colou a figura dos filhotes de pássaro (Figura 2), que segundo ele representa bem a família: “comida, comida, comida!". A preocupação com o excesso de peso também foi representada em diversas figuras que sugeriram formas para emagrecer, como atividade física e "fechar a boca".

Não observamos nenhum movimento da família de apoio ao processo de emagrecimento de Carlos. Segundo Mira: "Aqui ninguém faz dieta, não. Ninguém nunca fez." Lúcio complementa: "A dieta aqui é o seguinte: você vai almoçando e já vai pensando o que vai comer na janta". Para Sílvio o problema é o que eles comem:

"O pessoal aqui de casa come demais, além do povo comer 


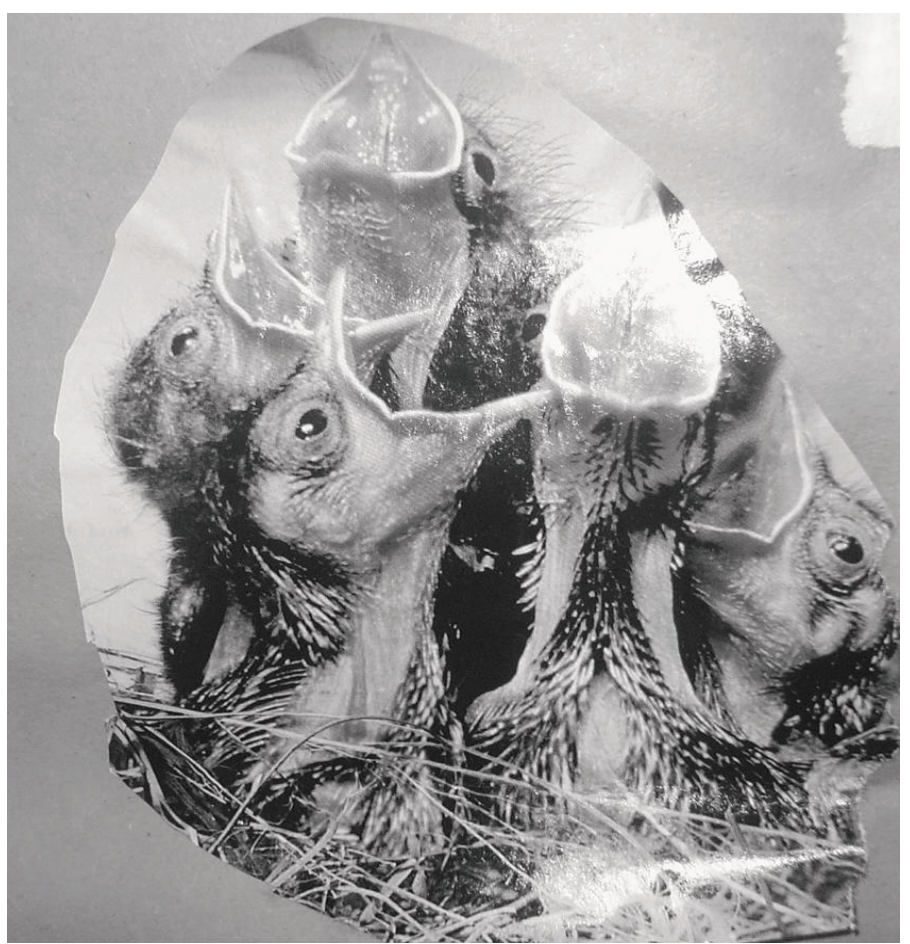

Figura 2. Recorte da colagem que representa a família em relação à alimentação.

demais a comida é chegada na gordura. Minha mãe faz a comida, frita a carne e deixa ela lá de molho dentro da gordura."

Quando a pesquisadora perguntou para Carlos sobre como sua família se comporta quando ele está em dieta. Ele respondeu:

"Ah! Vive malhando. O médico mandou comer seis vezes, se eu fizer isso aqui, eles falam que eu tô comendo demais. Daí, eu não respondo, fico na minha."

\section{Discussão}

A história de obesidade na família Oliveira revela uma característica transgeracional desse sintoma. Tanto a família da mãe quanto a família do pai de Carlos possui várias pessoas com obesidade. Na família nuclear, o pai, três irmãos e uma irmã de Carlos apresentam a doença. Esse dado, observado nogenograma familiar da família Oliveira, corrobora com os resultados do estudo transversal e da revisão da literatura, que também encontraram uma alta prevalência de história familiar de obesidade. Apesar de vários estudos (Francischi et al., 2000; Jebb, 1997; Ramos \& Barros Filho, 2003) apontarem para a influência genética como principal responsável pela transmissão desse sintoma de uma geração para outra, vamos enfocar aqui um outro aspecto, o papel desse sintoma na manutenção da estabilidade emocional da família através das gerações.

Apesar do histórico familiar, a obesidade na família Oliveira não surgiu na infância como o esperado por Ramos e Barros Filho (2003), que identificaram que uma criança cujo pai ou a mãe é obeso tem $40 \%$ de chance de se tornar obesa. Na família Oliveira todos os filhos obesos desenvolveram o sintoma após os 20 anos e, conforme Coutinho (1998), o ganho de peso nos homens relacionou-se ao sedentarismo advindo do trabalho na fase adulta, e na mulher mostrou íntima ligação ao ganho de peso gestacional.

Nesse sentido, vale ressaltar um aspecto da dinâmica da família Oliveira que demonstra uma dificuldade de adaptação familiar às diferentes fases do Ciclo de Vida. Apesar de a família se encontrar no "estágio tardio de vida", a fase anterior "lançando os filhos e seguindo em frente" parece não ter sido concluída pela família. Carter e McGoldrick (1989/1995) afirmam que nesse estágio o indivíduo busca a sua autonomia e diferenciação da família de origem e estabelece objetivos pessoais. Em alguns casos, pode acontecer do jovem não conseguir entrar nesse estágio, permanecendo um "adolescente em casa", ou pulando esse processo desenvolvimental por meio de um casamento prematuro, por exemplo. Os pais, por sua vez, tanto podem deixar seus filhos partirem, como podem enredá-los na teia familiar. Nesses casos, a família organiza-se de forma a dificultar a saída de seus filhos de casa em vez de ajudá-los a consolidar seu processo de individuação e construção de uma vida separada e independente. A figura de D. Lila na família estudada confirma essa colocação das autoras citadas acima, pois ela mantém todo o sistema sob o seu domínio. Todos os filhos contam seus problemas para ela, ela "sabe de tudo". Essa forte figura materna também foi identificada nos estudos sobre obesidade infantil (Morrissette \& Taylor, 2002; Otto, 2007; Prado, 2005).

Pesquisa recente com a população brasileira (Wendling \& Wagner, 2005) revela que os pais têm incentivado a permanência de seus filhos em casa por meio do aumento de regalias, cuidados e concessões, como, por exemplo, a permissão para dormir com o(a) namorado(a) no domicílio parental. A família Oliveira enfrenta dificuldades para se adaptar a essa fase. Três filhos adultos permanecem morando com a mãe, sendo que um deles 
trouxe também a namorada, o que demonstra uma dificuldade de se afastar da família de origem e assumir uma vida mais autônoma. Almerinda teve uma filha de um relacionamento passageiro e nunca saiu da casa da mãe. Carlos, que também mora com a mãe, assim como Almerinda, apresenta dificuldades em manter relações extrafamiliares, o que demonstra uma dificuldade da família em promover a autonomia dos seus membros e seu envolvimento social. Além disso, a maioria dos filhos e netos frequentam a casa de Dona Lila mais de três vezes por semana, sendo que um dos netos mora com a avó desde a separação dos pais. Nesse aspecto, observa-se a dificuldade do sistema em adaptar-se às fases do ciclo de vida por supervalorizar o pertencimento à família e com isso dificultar a autonomia dos seus membros.

Dessa forma, ao contrário do esperado, a Família Oliveira difere das famílias com obesidade descritas por Ganley (1992) e por Otto (2007), por apresentar um alto grau de coesão familiar. Por outro lado, corrobora com o estudo de caso realizado por Ganley em 1986, que aponta que as famílias com obesidade seriam enredadas como as famílias psicossomáticas estudadas por Minuchin, Rosman e Baker (1978). Possivelmente essa diferença se deva ao método de coleta dos dados, visto que todos os estudos que identificaram um nível baixo de coesão foram realizados por meio da escala FACES III, preenchida apenas pelo membro sintomático, o que pode ter influenciado uma percepção de coesão diminuída, posto que essas pessoas apresentam dificuldade de expressar seus sentimentos e por isso podem se sentir menos apoiadas pelos familiares.

Ainda sobre o ciclo de vida, como a família é muito coesa - com fronteiras internas difusas e fronteiras externas rígidas, o sistema nuclear enfrenta vários momentos do ciclo de vida ao mesmo tempo. D. Lila vive o "estágio tardio da vida" (Carter \& McGoldrick, 1989/1995), em que enfrentou a perda do marido e vive de sua aposentadoria, ao mesmo tempo que convive com filhos adultos que ainda não conquistaram sua autonomia, e cuida de uma neta adolescente e um neto de 8 anos que vivem com ela. Como a fase anterior do ciclo de vida não foi superada, D. Lila ainda lida com questões que já deveriam ser gerenciadas pelos seus próprios filhos.

Para Minuchin (1974/1982) a dificuldade que os sistemas aglutinados apresentam de adaptação à mudança decorre da excessiva rapidez e intensidade com que essas famílias respondem a qualquer variação do cotidiano. O comportamento de um membro afeta de imediato todos os outros e tem rápidas repercussões nos subsistemas. As fronteiras interpessoais são difusas, com os membros da família se intrometendo nas ideias, sentimentos e comunicações uns dos outros. Na família Oliveira todos falam ao mesmo tempo, sem respeitar o espaço do outro. Durante a entrevista, algumas pessoas colocaram suas preocupações e sentimentos, mas essas falas não foram acolhidas ou respondidas pelos demais. Quando algum assunto tornava-se sério ou tenso, logo um dos membros fazia uma piada e todos riam e mudavam de assunto rapidamente.

Essa forma de comunicação é denominada porWatzlawick, Beavin e Jackson (1967/1993) como desqualificação. Segundo os autores, existem quatro maneiras de responder a um emissor: confirmando, rejeitando, utilizando um sintoma ou desqualificando. Com poucas exceções, confirmar, rejeitar ou utilizar um sintoma são formas saudáveis de comunicar-se, enquanto desqualificar tende a gerar incertezas, por ser uma "resposta que não responde". A desqualificação frequentemente opera na comunicação de pessoas que querem rapidamente evadir-se de situações que, de alguma forma, soam difíceis. $\mathrm{Na}$ tentativa de esquivar-se do compromisso inerente a qualquer tipo de comunicação, essas pessoas tentam não comunicar, utilizando-se de mecanismos como o da Família Oliveira de todos começarem a falar enquanto alguém está falando, impossibilitando-o de prosseguir. Outras formas de desqualificação também foram observadas nessa família, como: frases incompletas, declarações contraditórias, mudanças bruscas de assunto, interpretações errôneas e interpretações literais de metáforas. A utilização sistemática desse mecanismo comunicacional pode trazer problemas para o sistema, visto que, além de invalidar a comunicação, possibilita que a família evite lidar com os conflitos interpessoais.

Nesse sentido, Satir (1964/1988) enfatiza a importância da comunicação no comportamento interacional e postula a ideia de que a doença familiar é derivada de métodos inadequados de comunicação entre os membros da família. Para a autora, os membros de famílias funcionais se manifestam com clareza, deixando aparecer abertamente o que pensam e sentem, e tratam a presença das diferenças mais como oportunidades de aprender e crescer do que como ameaça ou sinal de conflito. Além disso, empregam efetivamente seus recursos para solucionar os problemas do grupo familiar, ao mesmo tempo em que se preocupam com as necessidades emocionais de cada membro. Nas famílias disfuncionais, o fluxo do seu comportamento é impedido pela emoção não expressada, o que as fazem perder sua flexibilidade e vitalidade e, consequentemente, apresentarem sintomas para manter sua homeostase. Dessa forma, a obesidade pode ser uma forma de manter a estabilidade das relações familiares de famílias com dificuldade de lidar com a expressão de sentimentos de seus membros.

Essa hipótese é fortalecida pelas pesquisas de Amato Neto e Santoro (2006) e Ganley (1986; 1992), que identificaram algumas características da comunicação de pessoas e famílias com obesidade. Amato Neto e Santoro (2006) observaram que indivíduos obesos assumem menos as suas carências do que pessoas com peso normal temem defender seus direitos, fazer e receber elogios e pedidos com muita frequência. Ganley (1986; 1992), em seus dois estudos com famílias com obesidade, observou que os membros desses sistemas apresentavam dificuldade de lidar com a raiva, não compartilhavam seus sentimentos e evitavam conflitos.

Além disso, no estudo de caso realizado em 1986, Ganley, estudando uma família com obesidade, identificou que os membros do sistema negavam a existência dos problemas identificando, como único problema familiar, a obesidade da esposa. A família Oliveira apresenta uma característica semelhante, pois apesar de vários membros estarem bem acima do peso, é a obesidade de Carlos que os incomoda. Dessa forma, parece que Carlos é o paciente identificado da família, aquele que, segundo Minuchin e Fishman (1981/1990), carrega o sintoma, mantendo a homeostase familiar ao mesmo tempo 
que empurra a família para a mudança.

Para Andolfi, Angelo, Menghi e Nicolo-Corigliano (1983/1984) esse duplo significado do comportamento sintomático tanto representa uma transformação no funcionamento de coesão quanto é um sinal da dor e sofrimento resultantes das restrições impostas sobre cada membro da família. Nesse sentido, Ackerman (1958/1986) afirma que o conflito interpessoal afeta o conflito intrapsíquico e vice-versa, podendo estimular o crescimento ou predispor o surgimento de sintomas que, para o autor, são resultado da internalização dos conflitos familiares patológicos persistentes. Esse processo decorre da incapacidade do sistema de conter os efeitos destrutivos do conflito devido a um baixo nível de adaptação do sistema familiar. Nesse aspecto, é importante ressaltar que a cirurgia de redução de estômago terá influência sobre todo o sistema e que o sucesso desse tratamento dependerá de como a família vai se adaptar a esse processo.

Uma outra característica da dinâmica da família Oliveira é o isolamento social. Segundo Minuchin (1974/1982), as famílias aglutinadas sentem seu pertencimento ameaçado pelas relações de seus membros com sistemas extrafamiliares. A família Oliveira não mantém relações interpessoais com vizinhos ou amigos.

Nesse sentido, como afirmam Andolfi, Angelo, Menghi e Nicolo-Corigliano (1983/1984), o sistema dificulta o crescimento dos seus membros que não conseguem testar novos aspectos de si mesmos, fazendo com que as pessoas coexistam apenas como uma função dos outros. Assim, cada indivíduo acha-se forçado a ser sempre aquilo que o sistema impõe. Essa cronificação das funções familiares também foi observada na família Oliveira. A caracterização feita pelos irmãos de si mesmos e dos demais, mostra claramente o que se espera que cada um faça no núcleo familiar. Almerinda foi apontada com "zangada", Sílvio como "atleta", Mônica como "cuidadora", Lúcio como "piadista" e Carlos como "gordo". Em um sistema no qual pré-existem expectativas específicas sobre o papel ou função de cada um, a individuação de cada membro pode ser prejudicada, visto que a ausência de limites interpessoais claros faz com que seja impossível que qualquer indivíduo exista por si próprio. Andolfi, Angelo, Menghi e Nicolo-Corigliano (1983/1984) salientam que nesse tipo de funcionamento familiar qualquer ato de independência é traduzido como traição. Nesse sentido, a obesidade pode ser entendida como uma forma do indivíduo manter-se leal ao sistema, e ao mesmo tempo uma forma da família responder às demandas por mudanças naturais ao ciclo de vida sem mudar sua estrutura.

Outro fator importante que demonstra a dificuldade da família em promover a diferenciação de seus membros é a presença de sintomas relacionados à saúde emocional na quarta geração. Três adolescentes estão em terapia em um Centro de Atendimento voltado para adolescentes da cidade onde moram. Esse dado pode revelar o agravamento do sintoma através das gerações. Bowen (1979/1991), quando fala sobre o processo de transmissão multigeracional na família, afirma que este conceito remete a uma doença emocional, não apenas no indivíduo, mas também na família nuclear nas várias gerações. O sintoma é, então, resultado da sequência multigeracional na qual todos os membros da família são atores. O pesquisador salienta que este processo tende a manifestar-se em relação aos indivíduos menos diferenciados num grupo familiar e essa baixa taxa de diferenciação transmite-se através das gerações, agravandose. Dessa forma, o sintoma "obesidade" parece não ser mais suficiente para manter a estabilidade emocional da família Oliveira, que vem gerando novos sintomas como forma de diminuir a ansiedade e o estresse ocasionado pela dificuldade de diferenciação dos seus membros, que é aumentada a cada geração.

Uma característica interessante da família Oliveira é a importância da alimentação na dinâmica familiar. Tanto na colagem como durante as visitas esse foi o principal tema abordado pelo sistema. Um dos membros escolheu uma foto de filhotes de pássaros famintos para representar a família, usando a expressão "comida, comida, comida!" (Figura 2). Outras frases como "aqui todo mundo come muito", "nós nos reunimos no final de semana para conversar e comer", "o problema aqui é a comida", foram muito frequentes. Essa preocupação com a comida foi apontada por Campos (1993) como uma característica de pessoas obesas por hiperfagia. Parece que o sistema familiar focaliza toda a sua ansiedade na alimentação, que é o principal tema dos encontros entre os membros.

Nesse aspecto, a afirmação de Kathalian (1992) de que, para pessoas com obesidade, o ato de comer é tido como tranquilizador, parece combinar com nossas observações a respeito da família Oliveira. De fato, a sensação de pertencimento ao sistema se dá através da alimentação. Sílvio diz "aqui todo mundo come muito" e todos os membros concordam. Essa utilização explícita do processo alimentar como forma de coesão familiar, condiciona os membros a práticas alimentares que favorecem o desenvolvimento da obesidade. Assim, os membros que não querem engordar precisam encontrar formas compensatórias para a superalimentação. Sílvio, por exemplo, pratica atividade física regularmente, Mônica e Gina reduzem o consumo de alimentos durante a semana para, no sábado e domingo, na casa da mãe, poder "comer à vontade". Os demais membros adultos ou estão obesos ou com sobrepeso.

O curioso desse sistema é que nenhuma das crianças da família apresenta obesidade, pelo contrário, todas elas encontram-se com peso saudável. Possivelmente, isso se deve à qualidade da alimentação da família, que é rica em frutas e vegetais e à atividade física das crianças, posto que, como a família é grande, com muitas crianças, elas passam muito tempo brincando e correndo, o que auxilia no controle do peso. Contudo, a profecia auto-realizadora dessa família - conforme o conceito postulado por Watzlawick, Beavin e Jackson (1967/1993) - é que seus descendentes serão adultos obesos. As tias apontam uma das adolescentes como obesa, sendo que sequer a menina apresenta sobrepeso.

De certa forma, a família gira em torno da alimentação e os membros que não são obesos se esforçam para resistir "às tentações de D. Lila", que são ricas em gordura saturada. O interessante é que D. Lila parou de fazer alguns pratos a pedido de alguns de seus filhos, mas ensinou Carlos a realizá-los. Assim, mesmo que D. Lila ceda aos apelos de alguns de seus filhos para não fazer "pratos que engordam", todos continuam comendo as mesmas preparações, só que feitas por Carlos. O sistema, 
então, permanece com o mesmo funcionamento, não ocorrendo nenhuma mudança nos hábitos alimentares - caracterizado pelo alto consumo de gorduras e açúcares simples.

Assim, é possível que a família Oliveira apresente dificuldades para se adaptar ao processo pós-cirúrgico de Carlos. A mudança brusca de sua alimentação poderá trazer à tona conflitos encobertos pelo sintoma obesidade e o sistema, na tentativa de manter-se sem mudanças, poderá apresentar outros sintomas em outros membros da família.

\section{Considerações Finais}

O estudo de caso mostrou algumas similaridades quanto ao funcionamento de sistemas com obesidade descritos na literatura. A família possui fronteiras internas difusas e externas rígidas, pouco lazer, ênfase à lealdade familiar, forte ligação entre alimentação, afetividade e pertencimento, obesidade vista como único problema familiar e evitação de conflitos.

Assim, o processo alimentar na família de pacientes obesos parece estar intimamente ligado às interações familiares. O que, como, onde e com quem se come são características importantes da identidade familiar, podendo, para algumas famílias, ser a principal expressão de vínculo entre os seus membros. Nesse aspecto, mudanças no padrão alimentar influenciam diretamente a dinâmica da família, podendo, dependendo da capacidade de adaptação do grupo e do nível de coesão entre seus componentes, gerar resistência dos familiares a mudanças individuais de dieta.

Dessa forma, para que o tratamento nutricional seja efetivo em longo prazo, ele precisa modificar o foco e a forma de ação. $\mathrm{O}$ foco deve ampliar-se do individual para o familiar e a forma deve elevar a família à autora e atora das mudanças alimentares. De fato, são poucos os nutricionistas no mercado com formação para interagir e levar em consideração o grupo familiar. Talvez um trabalho em conjunto entre nutricionista e terapeuta de família seja o mais adequado nesses casos.

Por fim, gostaríamos de salientar a importância da inclusão da terapia familiar no pré e pós-operatório de pacientes com obesidade, como forma de facilitar a adaptação familiar à nova condição de vida do paciente. Como vimos, a obesidade não se limita ao indivíduo, ela está ligada ao sistema familiar como um todo e, portanto, precisa ser tratada de forma sistêmica. Precisamos expandir de um olhar multiprofissional focado no indivíduo para um olhar voltado para o contexto das relações do paciente. Se conseguirmos mudar o nosso olhare incluir a família no tratamento da obesidade, não como fonte de suporte, mas como agente primordial de mudança, possivelmente alcançaremos resultados melhores em longo prazo.

\section{Referências}

Ackerman, N. W. (1986). Diagnóstico e tratamento das relações familiares. (M. C. R. Goulart, Trad.). Porto Alegre: Artes Médicas. (Obra original publicada em 1958)

Alexander, F. (1989). Medicina psicossomática: princípios e aplicações. Porto Alegre: Artes Médicas.

Amato Neto, A., \& Santoro, C. F. (2006). Estudo sobre a relação entre obesidade e expressividade emocional: comparação de padrões de resposta em pessoas obesas e não obesas. Boletim de Iniciação Científica em Psicologia, 7(1), 41-63.

Andolfi, M., Angelo, C., Menghi, P. E., \& Nicolo-Corigliano, A. N. (1984). Por Trás da Máscara Familiar. (M. C. R. Goulart, Trad.). Porto Alegre: Artes Médicas. (Obra original publicada em 1983)

Barbarin, O. A., \& Tirado, M. (1985). Enmeshment, family processes, and successful treatment of obesity. Family Relations, 34(1), 115-121.

Bernardi, F., Cichelero, C., \&Vitolo, M. R. (2005). Obesidade: atualização sobre sua etiologia, morbidade e tratamento. Revista de Nutrição, 18(1), 85-93.

Boszormenyi-Nagy, I., \& Spark, G. (1973). Lealtades Invisibles. Buenos Aires: Amorrortu.

Bowen, M. (1991). De la familia al individuo (B. E. A. Lonnné, Trad.). Buenos Aires: Paidos. (Obra original publicada em 1979)

Campos, A. L. R. (1993). Aspectos psicológicos da obesidade. Pediatria Moderna, 29, 129-133.

Carter, B., \& McGoldrick, M. (1995). As mudanças do ciclo de vida familiar. (M. A. V. Veronese, Trad.) Porto Alegre: Artes Médicas. (Obra original publicada em 1989)

Cobelo, A. W., Saikali, M. O., \& Schomer, E. Z. (2004). A abordagem familiar no tratamento da anorexia e bulimia nervosa. Revista de Psiquiatria Clínica. 31(4), 184-187.

Conrad, S. W. (1954). The psychological implications of overeating. Psychiatric Quarterly, 28, 211-224.

Cordás, T. A., Lopes Filho, A. P., \& Segal, A. (2004). Transtorno alimentar e cirurgia bariátrica: relato de caso. Arquivo Brasileiro de Endocrinologia e Metabolismo, 48(4), 564-571.

Coutinho, W. (1998). Obesidade: conceitos e classificação. In M. A. A. Nunes, J. C. C Appolinário, A. L. G. Abuchaim \& W. Coutinho (Orgs.), Transtornos alimentares e obesidade (pp.197-203). Porto Alegre: Editora Artes Médicas Sul.

Cronin, B. S., \& Mac Donough, A. B. (1987). Nutrition management of morbid obesity in conjunction with surgical intervention. Topics in Clinical Nutrition, 2(2), 59-68.

Cruz, M. R. R., \& Morimoto, I. M. I. (2004). Intervenção nutricional no tratamento cirúrgico da obesidade mórbida: resultados de um protocolo diferenciado. Revista de Nutrição, 17(2), 263-272.

Donato, A., Osório, M. G. F., Paschoal, P. V., \& Marum, R. H. (2004). Obesidade. In S. R. Busse (Org.), Anorexia, Bulimia e Obesidade (pp. 329-361). Barueri: Manole.

Féres-Carneiro, T. (1983). Família: diagnóstico e terapia. Rio de Janeiro: Zahar editores.

Francischi, R. P. P., Pereira, L. O., Freitas, C. S., Klopfer, M., Santos, R. C., Vieira, P., \& Lancha Júnior, A. H. (2000). Obesidade: atualização sobre sua etiologia, morbidade e tratamento. Revista de Nutrição, 13(1), 17-28.

Ganley, R. M. (1986). Epistemology, family patterns and psychosomatics: the case of obesity. Family Process, 25, 437-431.

Ganley, R. M. (1992).Family patterns in obesity: with consideration of emotional eating and restraint. Family Sistems Medicine, 10(2), 181-199.

Hamburger, W. W. (1951).Emotional aspects of obesity. Medical Clinics of North America, 35, 483-499.

Jebb, S. A. (1997). Aetiology of obesity. British Medical Bulletin, 53(2), 264-285. Johnson, B., Brownell, K. D., St. Jeor, S. T., Brunner, R. L., \& Worby, M. (1997). Adult obesity and functioning in the family of origin. International Journal of Eating Disorders, 22, 213-218.

Kathalian, A. (1992). Obesidade: um desafio. In J. Mello Filho (Org.), Psicossomática hoje (pp. 273-278). Porto Alegre: Artes Médicas.

Marshall, J. R., \& Neil, J. (1977). The removal of a psychosomatic symptom: effects on the marriage. Family Process, 16, 273-280.

Minuchin, S., Rosman, B. L., \& Baker, L. (1978). Psychosomatic families: anorexia nervosa in context. Cambridge: Harvard University Press.

Minuchin, S. (1982). Familias: funcionamento e tratamento (J.A. Cunha, Trad.). Porto Alegre: Artes Médicas. (Obra original publicada em 1974). 
Minuchin, S., \&Fishman, H.C. (1990). Técnicas de terapia familiar (C. Kinsch \& M. E. F. R. Maia, Trads.). Porto Alegre: Artes Médicas. (Obra original publicada em 1981)

Morrissette, P. J., \& Taylor, D. (2002).Family counseling and childhood obesity: a review of approaches. The Family Journal, 10(1), 19-26.

Oliveira, V. M., Linardi, R. C., \& Azevedo, A. P. (2004). Cirurgia bariátrica: aspectos psicológicos e psiquiátricos. Revista de Psiquiatria Clínica, 31(4), 199-201.

Otto, A. F. N. (2007). Obesidade e Transtorno da Compulsão alimentar Periódica: um estudo sobre a dinâmica familiar. (Dissertação de Mestrado). Universidade Católica de Brasília.

Prado, M. C. C. A. (2005). "O excesso de alguma coisa é a falta de alguma coisa." Mas o que estará faltando? A obesidade mórbida em questão. In T. Feres-Carneiro (Org.), Família e casal: efeitos da contemporaneidade (pp. 200-222). Rio de Janeiro: PUC-Rio.

Ramos, A. M. P. P., \& Barros Filho, A. A. (2003). Prevalência da obesidade em adolescentes de Bragança Paulista e sua relação com a obesidade dos pais. Arquivos Brasileiros de Endocrinologia e Metabologia, 47(6), 663-668.
Satir, V. (1980). Terapia do grupo familiar: um guia para teoria e técnica. (A. Nolli, Trad.) Rio de Janeiro: Francisco Alves. (Obra original publicada em 1964)

Segal, A., \& Fandiño, J. (2002). Indicações e contra-indicações para realização das operações bariátricas. Revista Brasileira de Psiquiatria, 24(3), 68-72.

Shikora, S. A. (2000). Surgical treatment for severe obesity: the state-of-the-art for the new millennium. Nutrition in ClinicalPractice, 15(1), 13-22.

Watzlawick, P., Beavin, J. H., \& Jackson, D. D. (1993). Pragmática da comunicação humana: um estudo dos padrões, patologias e paradoxos da interação (A.Cabral, Trad.). São Paulo: Editora Cultrix. (Obra originalpublicada em 1967)

Wendling, M. I., \& Wagner, A. (2005).Saindo da casa dos pais: a construção de uma nova identidade familiar. In A. Wagner (Org.), Como se perpetua a familia? A transmissão dos modelos familiares (pp. 123-134). Porto Alegre: EDIPUCRS.

Whitaker, C. A., \& Bumberry, W. M. (1990). Dançando com a família (R.E. Starosta, Trad.). Porto Alegre: Artes Médicas. (Obra original publicada em 1988).

Ana Flávia Nascimento Otto, mestre em Psicologia Clínica pela Universidade Católica de Brasília, é Analista Administrativo da Agência Nacional de Energia Elétrica - ANEEL. E-mail: anaotto30@yahoo.com.br Maria Alexina Ribeiro, doutora em Psicologia Clínica pela Universidade de Brasília, é professora Doutora da Universidade Católica de Brasília. Endereço: Universidade Católica de Brasília. QS 07 lote 01- Águas Claras,Taguatinga. CEP: 72030-170 - Brasilia, DF - Brasil Telefone: (61) 33569197. E-mail: alexina@solar.com.br 